\title{
Total copy number variation as a prognostic factor in adult astrocytoma subtypes
}

\author{
Kanish Mirchia', Adwait Amod Sathe², Jamie M. Walker ${ }^{3,4}$, Yelena Fudym¹, Kristyn Galbraith', Mariano S. Viapiano ${ }^{5,6}$,
} Robert J. Corona ${ }^{1}$, Matija Snuderl ${ }^{7}$, Chao Xing ${ }^{2,8,9}$, Kimmo J. Hatanpaa ${ }^{10}$ and Timothy E. Richardson ${ }^{1 *}$

\begin{abstract}
Since the discovery that IDH1/2 mutations confer a significantly better prognosis in astrocytomas, much work has been done to identify other molecular signatures to help further stratify lower-grade astrocytomas and glioblastomas, with the goal of accurately predicting clinical outcome and identifying potentially targetable mutations. In the present study, we subclassify 135 astrocytomas (67 IDH-wildtype and 68 IDH-mutant) from The Cancer Genome Atlas dataset (TCGA) on the basis of grade, IDH-status, and the previously established prognostic factors, CDK4 amplification and CDKN2A/B deletion, within the IDH-mutant groups. We analyzed these groups for total copy number variation (CNV), total mutation burden, chromothripsis, specific mutations, and amplifications/ deletions of specific genes/chromosomal regions. Herein, we demonstrate that across all of these tumor groups, total CNV level is a relatively consistent prognostic factor. We also identified a trend towards increased levels of chromothripsis in tumors with lower progression-free survival (PFS) and overall survival (OS) intervals. While no significant differences were identified in overall mutation load, we did identify a significantly higher number of cases with mutations in genes with functions related to maintaining genomic stability in groups with higher mean CNV and worse PFS and OS intervals, particularly in the IDH-mutant groups. Our data further support the case for total CNV level as a potential prognostic factor in astrocytomas, and suggest mutations in genes responsible for overall genomic instability as a possible underlying mechanism for some astrocytomas with poor clinical outcome.
\end{abstract}

Keywords: Copy number variation, CNV, Astrocytoma, Glioma, Glioblastoma, GBM, TCGA

\section{Introduction}

Diffuse gliomas are among the most common primary CNS tumors, representing approximately $27 \%$ of all primary brain tumors $[29,30]$. Due to their infiltrative nature, these tumors are surgically incurable, although the exact prognosis depends on numerous histologic and molecular factors. The standard of care now dictates molecular classification of gliomas based on $I D H 1 / 2 \mathrm{mu}-$ tation status as $I D H$-mutant gliomas have a significantly better prognosis than their $I D H$-wildtype grade-matched counterparts [25]. While histologic grade shows correlation with overall survival within these molecular

\footnotetext{
* Correspondence: RichaTim@Upstate.edu

${ }^{1}$ Department of Pathology, State University of New York, Upstate Medical University, Syracuse, NY 13210, USA

Full list of author information is available at the end of the article
}

groups, there remains significant heterogeneity in clinical outcome.

Since the widespread adoption of the 2016 WHO classification system, much work has been done to find further molecular markers to sub-stratify both $I D H$-mutant and $I D H$-wildtype astrocytomas in hopes of better predicting tumor behavior and outcome, including identification of secondary mutations, focal genetic alterations, methylation patterns, and multivariate prognostic models $[3,24,42,44]$. Within the $I D H$-wildtype groups, these studies have suggested that lower-grade gliomas (LGG) with EGFR amplification, gain of chromosome 7 and loss of 10, or TERT promoter mutations will have aggressive clinical courses and outcomes similar to $\mathrm{IDH}$ wildtype glioblastoma, regardless of histologic features. In $I D H$-mutant groups, lower-grade tumors with alterations in genes in the retinoblastoma pathway, including 
amplification of $C D K 4$ and deletion of $C D K N 2 A / B$, demonstrate significantly worse clinical behavior and shorter patient survival $[1,5,8,33]$.

Previous work has demonstrated that $I D H$-mutant glioblastomas have higher levels of total copy number variation $(\mathrm{CNV})$ across the entire genome and evidence of more frequent chromothripsis than lower-gradeIDHmutant astrocytomas [9]. We subsequently showed that in IDH-mutant grade II and III astrocytomas, this increased level of $\mathrm{CNV}$ was present before progression to glioblastoma in cases with exceptionally poor outcomes, defined by rapid progression to glioblastoma and short survival times after initial diagnosis [36, 37]. The poor outcome appeared to be directly correlated with overall $\mathrm{CNV}$, but not other factors, including mutation burden or differences in methylation profiles, suggesting that this large scale $\mathrm{CNV}$ pattern could potentially override the beneficial effect of $I D H$-mutant status.

To better understand the effect of CNV, we analyzed 135 astrocytic tumors from The Cancer Genome Atlas (TCGA) (67 IDH-wildtype and $68 \mathrm{IDH}$-mutant cases) with respect to clinical outcome, $\mathrm{CNV}$ levels, chromosomal and specific gene amplification and deletion events, chromothripsis, total mutation load, specific mutations in known glioma/GBM genes, and mutations in genes associated with overall genomic instability. Building on our previous results, we performed wide scale genomic analysis, on a framework of pre-established prognostic factors including grade, $I D H 1 / 2$-status, and the presence of $C D K 4$ amplifications or $C D K N 2 A / B$ deletions. With the exception of $2 I D H 1 / 2$-wildtype cases, $C D K 4$ amplification and $C D K N 2 A / B$ deletion were found to be mutually exclusive. We divided the cases into 5 groups: $I D H 1 / 2$-mutant LGG without CDK4 amplification or $C D K N 2 A / B$ deletion (Group 1), IDH1/2mutant LGG with either CDK4 amplification or $C D K N 2 A / B$ deletion LGG (Group 2), IDH1/2-mutant GBM (Group 3), IDH1/2-wildtype LGG (Group 4), and IDH1/2-wildtype GBM (Group 5).

We demonstrate that higher levels of CNV and chromothripsis are correlated with clinical outcome in the $I D H$-mutant groups, while the $I D H$-wildtype groups had uniformly high CNV levels and poor outcomes. Other prognostic factors appear to be inconsistent. We also identified a significantly higher number of mutations in genes involved with overall genomic stability, paralleling levels of overall CNV and chromothripsis, in the cases with worse prognosis. While defining the exact role of genes involved in progression may still be needed for development of individualized targeted therapies, use of CNV could potentially serve as a clinically impactful model for prognostication of different astrocytoma subtypes, and may aid in our understanding of the underlying biology of these tumor types.

\section{Methods}

\section{TCGA case selection}

Using the cBioportal interface, we performed a search of 380 glioblastoma cases and 539 lower-grade gliomas (LGG, defined here as WHO grade II-III) [6, 9, 14]. The original histologic diagnoses reported in TCGA included astrocytoma, oligoastrocytoma, anaplastic astrocytoma, anaplastic oligoastrocytoma, and glioblastoma. All cases were manually reclassified according the WHO 2016 criteria as diffuse astrocytomas (WHO grade II-IV) by histology, intact $1 \mathrm{p} / 19 \mathrm{q}$ status, and IDH1/2, ATRX, and TP53 status. Oligodendrogliomas were specifically excluded on the basis of $1 \mathrm{p} / 19 \mathrm{q}$ co-deletion, as these tumors have been shown to have different underlying molecular drivers and a more favorable clinical outcome as a group. All cases selected represented the first resection specimen and were segregated into lower-grade (WHO grades II and III) $[9,28,35]$ and GBM (WHO grade IV) within the IDH1/2 mutation groups. We identified 5 groups based on previously identified prognostic factors, including histologic grade, $I D H 1 / 2, C D K 4$, and $C D K N 2 A / B$ status $[1$, $8,25,31,45]$ and selected groups of TCGA cases that met these criteria: Group 1, IDH1/2-mutant LGG without $C D K 4$ amplification or $C D K N 2 A / B$ deletion $(n=24$, mean age $=38.8 \pm 1.9$ years); Group 2, IDH1/2-mutant, CDK4amplified $/ C D K N 2 A / B$-deleted LGG $(n=22$, mean age $=$ $38.8 \pm 1.9$ years); Group 3, IDH1/2-mutant GBM ( $n=$ 22 , mean age $=40.5 \pm 2.7$ years); Group $4, I D H 1 / 2$-wildtype LGG $(n=25$, mean age $=54.0 \pm 2.6$ years $)$; Group 5 , IDH1/2-wildtype GBM $(n=42$, mean age $=62.8 \pm 1.7$ years) (Table 1$)$.

\section{Genetic and epigenetic analysis}

The gene expression (Illumina HiSeq, RNASeq) and DNA methylation data (Illumina Human Methylation 450) was downloaded for the selected TCGA cases and analyzed with TCGAbiolinks [10]. The Affymetrix SNP 6.0 microarray data normalized to germline for copy number analysis for the same TCGA cases was downloaded from Broad GDAC Firehose (http://gdac.broadinstitute.org/runs/stddata_2016_01_28/). The fraction of copy number alterations was calculated from the above data as the fraction of the genome with $\log 2$ of copy number $>0.3$ following the procedure used in cBioportal [14]. The mutation load is the number of nonsynonymous mutations seen in a sample. The differential analysis and visualization of mutations was done using Maftools [26]. The Ideogram for visualization of genome-wide copy number variation results was generated using Genome Decoration Page (https://www.ncbi.nlm.nih.gov/genome/tools/gdp). The pathway and network analyses were conducted using Qiagen's IPA tool (www.qiagen.com/ingenuity) and R 3.4.1 (http://www.R-project.org/). 
Table 1 Summary of available clinical, histologic, and molecular data from each astrocytoma subgroup analyzed

\begin{tabular}{|c|c|c|c|c|c|c|c|c|c|c|}
\hline Group & Tumor Type & $n$ & $\begin{array}{l}\text { Age at Onset } \\
\text { (years) }\end{array}$ & $\begin{array}{l}\text { Median } \\
\text { Progression-Free } \\
\text { Survival } \\
\text { (months) }\end{array}$ & $\begin{array}{l}\text { Median } \\
\text { Overall Survival } \\
\text { (months) }\end{array}$ & $\begin{array}{l}\text { Histologic Grade } \\
\text { (II/III/IV) }\end{array}$ & $\begin{array}{l}\text { CNV Level } \\
(\%)\end{array}$ & $\begin{array}{l}\text { Cases with } \\
\text { Chromothripsis }\end{array}$ & $\begin{array}{l}\text { Mutation } \\
\text { Count }\end{array}$ & $\begin{array}{l}\text { Instability } \\
\text { Gene Mutations }\end{array}$ \\
\hline 1 & $I D H$-mut LGG & 24 & $38.8 \pm 1.9$ & 95 & $>172$ & $12 / 12 / 0$ & $9.1 \pm 1.6$ & $2(8.3 \%)$ & $43 \pm 10.5$ & $1(4.1 \%)$ \\
\hline \multirow[t]{2}{*}{2} & IDH-mut CDK4I & & & & & & & & & \\
\hline & CDKN2A/B LGG & 22 & $38.8 \pm 1.9$ & 32 & 36 & $4 / 18 / 0$ & $21.3 \pm 2.5$ & $6(27.3 \%)$ & $33.3 \pm 1.3$ & $7(31.8 \%)$ \\
\hline 3 & IDH-mut GBM & 22 & $40.5 \pm 2.7$ & 10 & 33 & $0 / 0 / 22$ & $20 \pm 2.7$ & $9(40.9 \%)$ & $67.4 \pm 2.75$ & $8(36.4 \%)$ \\
\hline 4 & IDH-wt LGG & 25 & $54.0 \pm 2.6$ & 10.5 & 15.5 & $0 / 25 / 0$ & $19.9 \pm 1.8$ & $5(20.0 \%)$ & $64.9 \pm 16.7$ & $5(20.0 \%)$ \\
\hline 5 & IDH-wt GBM & 42 & $62.8 \pm 1.7$ & 6 & 13 & $0 / 0 / 42$ & $22.2 \pm 1.6$ & $11(26.2 \%)$ & $57.0 \pm 2.5$ & $10(23.8 \%)$ \\
\hline
\end{tabular}

\section{GISTIC analysis}

The GISTIC (Genomic Identification of Significant Targets in Cancer) 2.0 algorithm was used to identify regions of the genome that are significantly amplified or deleted between the 5 groups of $I D H 1 / 2$-mutant and wildtype astrocytoma cases [27]. Each area of CNV is assigned a G-score that considers the amplitude of the alteration as well as the frequency of its occurrence across samples. The false discovery rate (FDR) was then used to determine the relative significance of each abnormality. Each region predicted to be significantly different between the 5 groups was screened for tumor suppressor genes, oncogenes, and other genes associated with glioma and malignancy [2, 27]. GISTIC 2.0 analysis was run using GenePattern [32].

\section{Mutation analysis of genes involved in maintenance of genomic stability}

A group of genes with previously identified roles in cell proliferation and maintaining chromosomal stability were identified by a literature review and included the following genes: APC, ATM, ATR, BLM, BRCA1 (FANCS), BRCA2 (FANCD1), BUB1B, CHK1, CLSPN, DNA-PK (PRKDC), EME1, FANCA, FANCB, FANCC, FANCD2, FANCE, FANCF, FANCG, FANCI, FANCJ (BRIP1), FANCL, FANCM, FANCN (PALB2), FANCO (RAD51C), FANCP (SLX4), FANCQ, FANCR, FANCT (UBE2T), HUS1, LIG4, MUS81, NBN, POLK, POLN, RAD51, RAD52, REV3, SMC1, SNM1B, TOP1, TP53, $W R N$, and $X L F[7,16,36]$. Variant annotation was performed using COSMIC [13], dbSNP [39], ClinVar [22], CanProVar 2.0 [23], The 1000 Genomes Project [15], and FATHMM-MKL [40].

\section{Statistical analysis}

Differences in patient age, mutation burden, and CNV were evaluated using Analysis of Variance (ANOVA). Significance of survival curves were calculated using the Mantel-Cox test (Log-rank test). Proportion of cases with chromothripsis and mutations specifically associated with genome instability were calculated using Fisher's Exact test. Coefficients of variation ( $\mathrm{CNV}$ vs survival times) were calculated using Pearson correlation coefficient. All statistical calculations were performed with GraphPad Prism version 7.04 (GraphPad, La Jolla, CA).

\section{Results}

\section{Clinical characteristics}

As previously demonstrated [1, 8], IDH-mutant LGGs (group 1) had a significantly longer progression-free survival (PFS; median 95 months) and overall survival (OS; > 172 months) than $I D H$-mutant LGGs with $C D K 4$ amplifications or $C D K N 2 A / B$ deletions (group 2) (PFS 32 months, $p=0.0224$; OS 36 months, $p=0.0150$ ) and a significantly longer PFS and OS than $I D H$-mutant GBM (group 3) (PFS 10 months, $p=0.0032$; OS 33 months, $p=0.0081$ ). A significant difference was not found between $I D H$-mutant LGGs with $C D K 4$ amplifications or $C D K N 2 A / B$ deletions (group 2) and $I D H$-mutant GBM (group 3) in terms of PFS $(p=0.0769)$ or OS $(p=0.2892)$ (Fig. 1a-b). No significant difference was found between IDH-wildtype LGGs (group 4 ) and $I D H$-wildtype GBM (group 5) in terms of PFS ( $p=$ $0.2050)$ or OS $(p=0.9351)$ (Fig. 1c-d). Amplifications in $C D K 4$ and deletions in $C D K N 2 A / B$ did not have prognostic significance within the $I D H$-mutant GBM group in terms of PFS ( $p=0.8406)$ or OS ( $p=0.1471)$ (Fig. 2a-b).

No significant difference was identified in the median age of onset within the $I D H$-mutant groups 1-3, however there was a significant difference between the average age of onset in IDH-mutant LGG cases (38.8 \pm 1.9 years) and $I D H$-wildtype LGG cases $(54.0 \pm 2.6$ years $)(p<0.0001)$. There was also a significant difference in age of onset between IDH-wildtype LGGs $(54.0 \pm 2.6$ years $)$ and $I D H$ wildtype GBMs $(62.8 \pm 1.7$ years) $(p=0.0047)$. There was a trend toward higher histologic tumor grade identified between groups 1 and 2. All IDH1/2-wildtype LGG tumors (group 4) were WHO grade III by histology at initial diagnosis (Table 1).

\section{Total copy number analysis differences}

Mirroring the difference in clinical outcome, the total percentage of the genome with copy number alterations was low in the LGGs without CDK4 or $C D K N 2 A / B$ alterations and uniformly high in the other 4 groups 


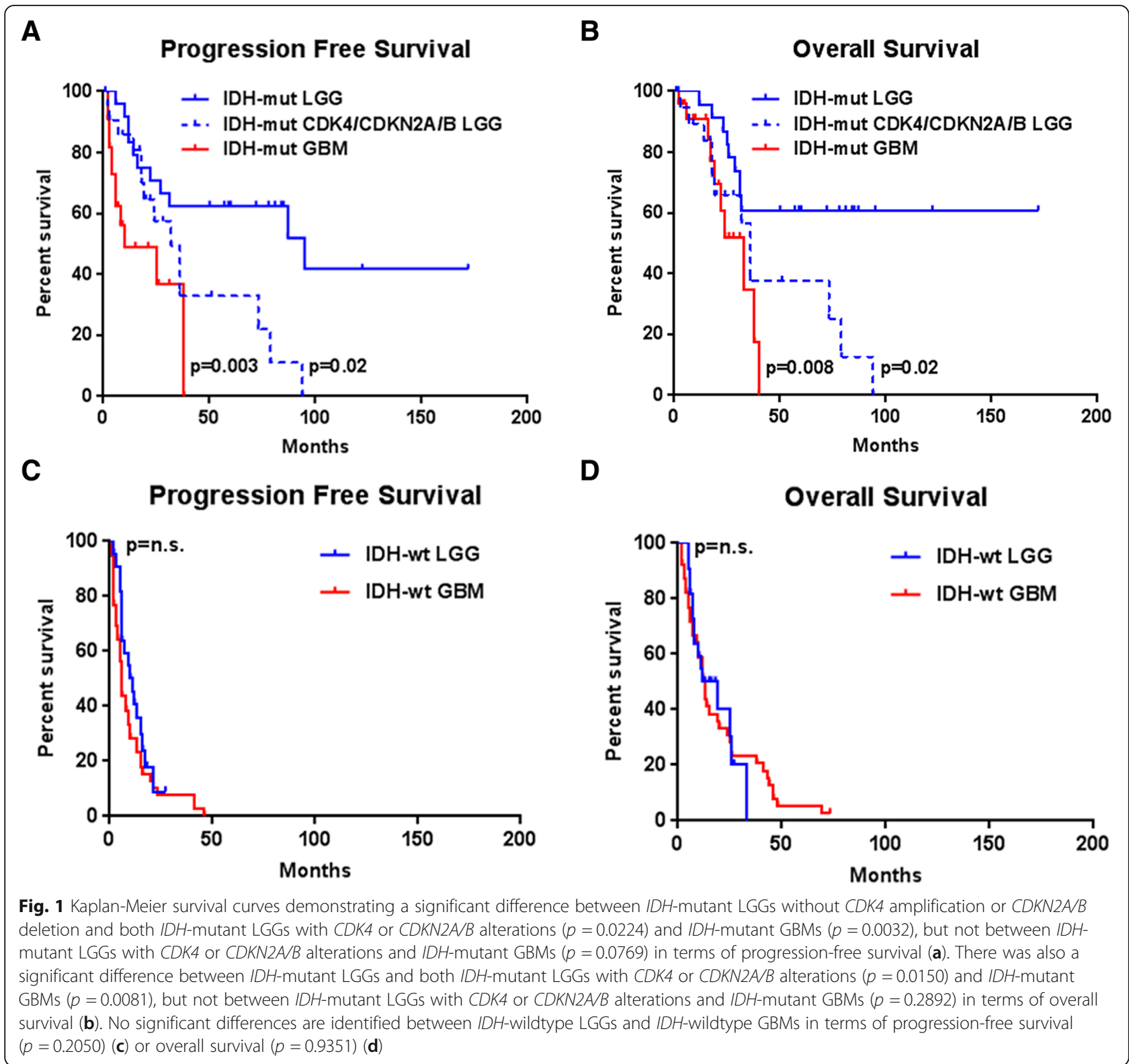

(Table 1). Total copy number variation was $9.1 \pm 1.6 \%$ in IDH-mutant LGGs (group 1), a significantly lower level than $I D H$-mutant LGGs with CDK4 amplification or $C D K N 2 A / B$ deletion (group 2) $(21.3 \pm 2.5 \%, p=0.0003)$ or $I D H$-mutant GBM (group 3$)(20.0 \pm 2.7 \%, p=0.0078)$. No significant difference was identified between any of the groups with statistically equivalent prognoses: group 2 vs group $3, p=0.7758$; group 3 vs group $5, p=0.5277$; or group 4 vs group $5, p=0.3732$ ) (Fig. $3 a, c)$. No significant difference was noted when comparing $I D H$-mutant GBM cases with $C D K 4$ amplification or $C D K N 2 A / B$ deletion to those without ( $p=0.5326)$ (Fig. 2c). These calculations could not be meaningfully performed in either $I D H$-wildtype group due to the high frequency of $C D K 4$ and $C D K N 2 A / B$ alterations.
In the $I D H$-mutant astrocytomas as a whole (groups $1-3)$, there was a statistically significant inverse correlation between the total copy number variation in each case and both the progression-free survival $(r=-0.3415$; $p=0.0047$ ) (Fig. 4a) and overall survival ( $r=-0.3098$; $p=0.0102$ ) (Fig. 4b). Due to the uniformly high CNV level and poor prognosis in the $I D H$-wildtype tumor groups 4 and 5, no significant correlation was established between CNV and PFS or OS within these groups.

\section{Chromosomal analysis and GISTIC}

Analysis of the $I D H$-mutant tumors (groups 1-3) revealed a heterogeneous assortment of genomic alterations with few consistent chromosomal regions with amplifications or deletions, although there is a clear increase in number 


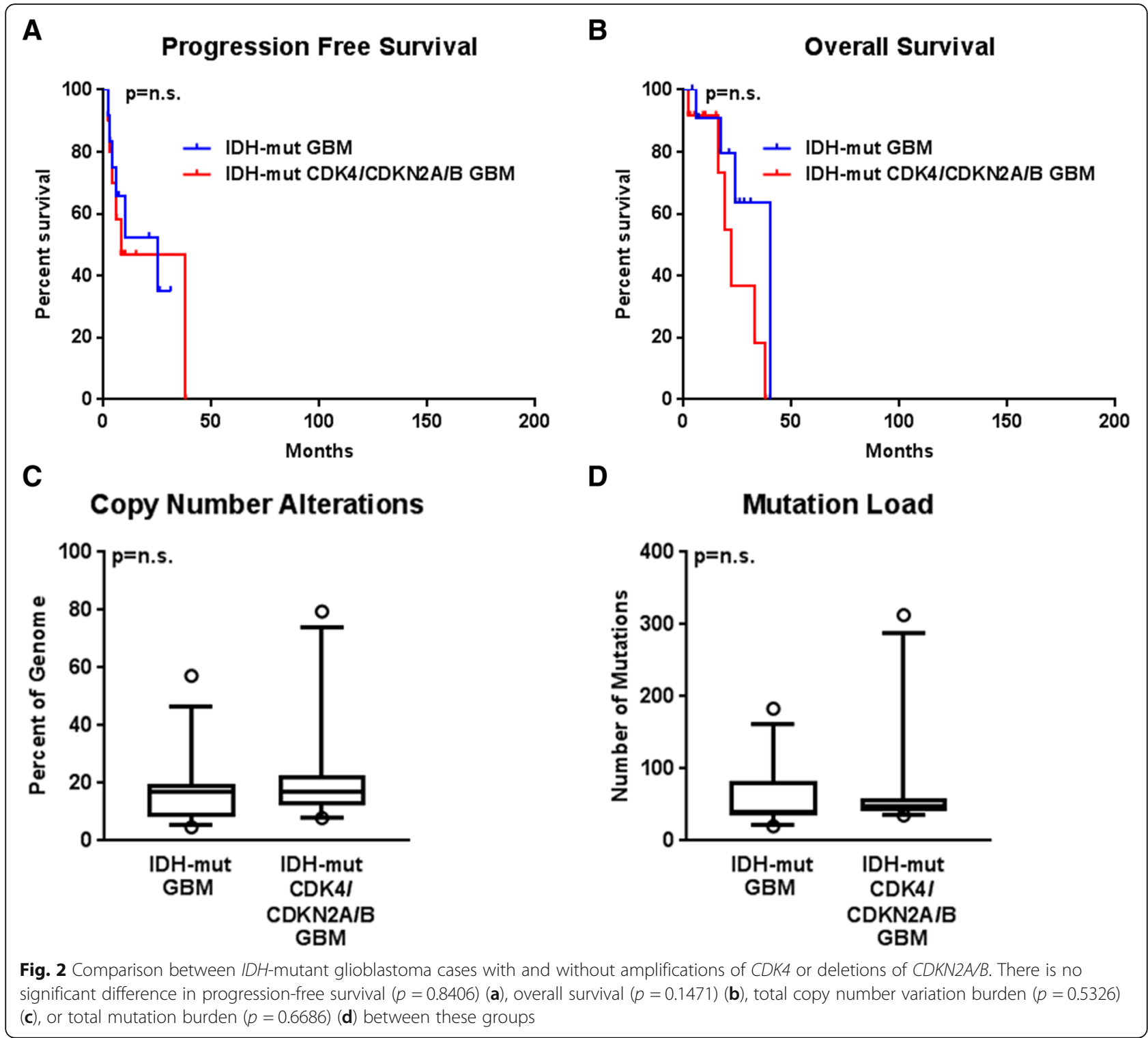

of overall alterations between the group $1 \mathrm{IDH}$-mutant LGGs and the group $2 \mathrm{IDH}$-mutant LGGs with $C D K 4$ amplification/CDKN2A/B deletion and group $3 \mathrm{IDH}$-mutant GBM (Fig. 5), quantified in Fig. 3a. Conversely, IDHwildtype LGGs and GBMs form a relatively homogeneous group with consistent amplifications, including large amplifications along chromosome 7, deletions on 9p, and deletions of chromosome 10 (Fig. 6).

As expected based on our case selection, Genomic Identification of Significant Targets In Cancer (GISTIC) analysis showed high levels of amplification of 12q14.1 (a region containing CDK4) in all gliomas with poor prognosis (i.e., groups 2, 3, 4, and 5) but not in group 1 . Similarly, 9p21.3 (a region containing CDKN2A) showed frequent deletions in groups $2,3,4$, and 5 but not in group 1. IDH-wildtype tumors had consistent amplifications of 7p11.2 (containing EGFR) and 1q32.1 and deletions of $1 \mathrm{p} 32.3$, but only IDH-wildtype GBM had consistent deletions at 10q23.31. Interestingly, $I D H$ mutant GBM and IDH-mutant LGGs with CDK4 amplification/CDKN $2 A / B$ deletion both had amplifications at 2p24.3 (a chromosomal region containing $M Y C N$ ). This was not identified in $I D H$-mutant LGGs with a good clinical outcome or in the $I D H$-wildtype tumors. Group 1 IDH-mutant LGGs had significant consistent amplifications at $3 \mathrm{p} 25.2,5 \mathrm{q} 31.1,8 \mathrm{q} 24.13,11 \mathrm{q} 24.2,13 \mathrm{q} 34$, $19 q 13.12, \mathrm{Xp} 22.32$, and Xq28, as well as consistent deletions at $3 \mathrm{p} 14.1,9 \mathrm{p} 24.2,11 \mathrm{p} 12,13 \mathrm{q} 14.3,14 \mathrm{q} 24.3$, and $\mathrm{Xq} 21.1$ that were not identified in any other tumor group (Fig. 7). All cytobands shown met the criterion of false discovery rate (FDR) $\leq 0.25$. The annotated cytobands met the criterion of FDR $\leq 0.05$. 


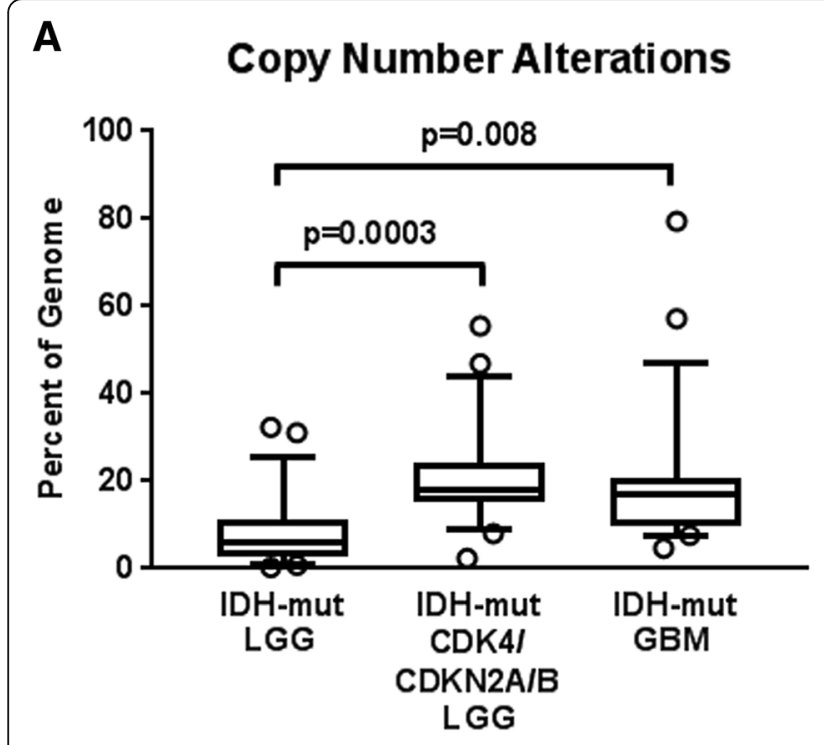

B

Mutation Load

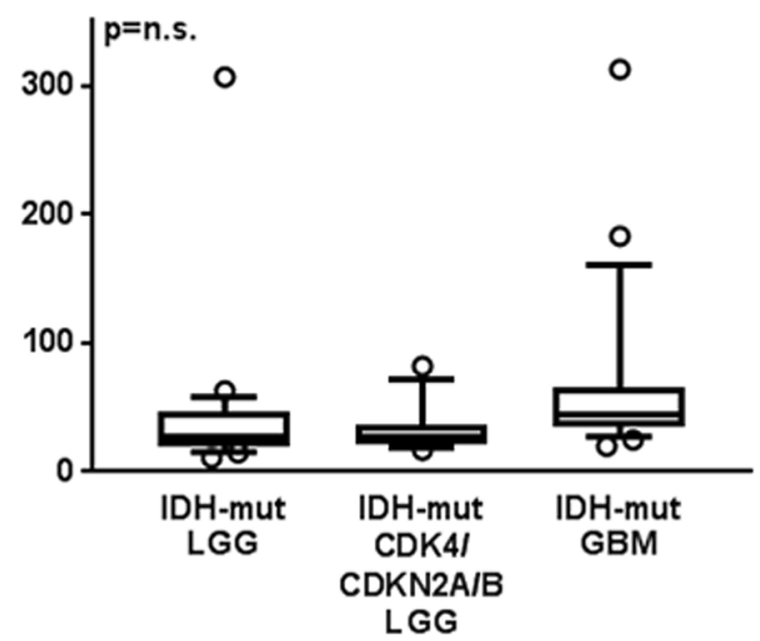

C

Copy Number Alterations

D
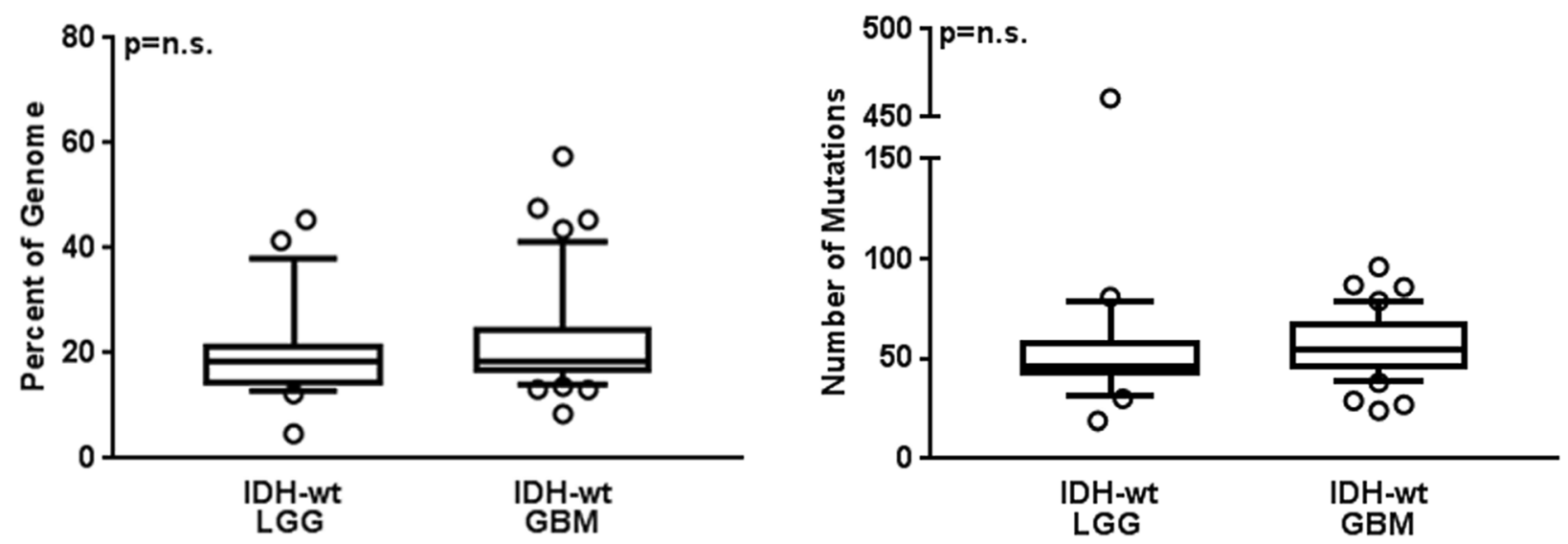

Fig. 3 Total copy number variation averages demonstrating a significant difference between IDH-mutant LGGs without CDK4 amplification or CDKN2A/B deletion and both IDH-mutant LGGs with CDK4 or CDKN2A/B alterations $(p=0.0003)$ and IDH-mutant GBMs $(p=0.0078)$, but not between IDH-mutant LGGs with CDK4 or CDKN2A/B alterations and IDH-mutant GBMs ( $p=0.7783)$ (a); no significant difference was found in total mutation burden between any group of IDH-mutant astrocytoma (b). There was no significant difference between IDH-wildtype LGGs and IDHwildtype GBMs in terms of overall copy number variation $(p=0.3732)$ (c) or total mutation burden $(p=0.5627)$ (d)

Amplifications and deletions in specific genes of interest were rare in the group $1 \mathrm{IDH}$-mutant LGGs, per our study design (Additional file 1: Figure S1). IDH-mutant astrocytomas with poor clinical outcomes (groups 2 and 3) also showed more frequent amplifications of GLI1, KIT, KDR, MYC, MYCN, GATA3, CCND2, and KRAS as well as more frequent deletions of PTEN, PTPRD, ATRX, and $R B 1$ (Additional file 2: Figure $\mathrm{S} 2$ and Additional file 3: Figure S3).

$I D H$-wildtype groups frequently had amplifications in EGFR, PDGFRA, CDK4, MDM2, MDM4, KIT, and KDR, as well as deletions in $C D K N 2 A / B$, and PTEN. CDK4 amplification and $C D K N 2 A / B$ deletion appear to be almost mutually exclusive, as they only occur together in one $I D H$-wildtype LGG case and one $I D H$-wildtype GBM case (2.3\% of cases with these alterations) (Additional file 4: Figure S4 and Additional file 5: Figure S5).

\section{Analysis of chromothripsis}

Chromothripsis, defined here as 10 or more alternating bands of amplifications and deletions in a single chromosome $[9,21]$, was identified in at least one tumor in each of the 5 groups analyzed (Table 1). Comparing individual groups, there was a significant difference in the number of cases with chromothripsis between group 1 LGGs without $C D K 4$ amplification or $C D K N 2 A / B$ deletion and group $3 \mathrm{IDH}$-mutant glioblastomas $(p=$ 0.0132) and a significant difference in group 1 LGGs 

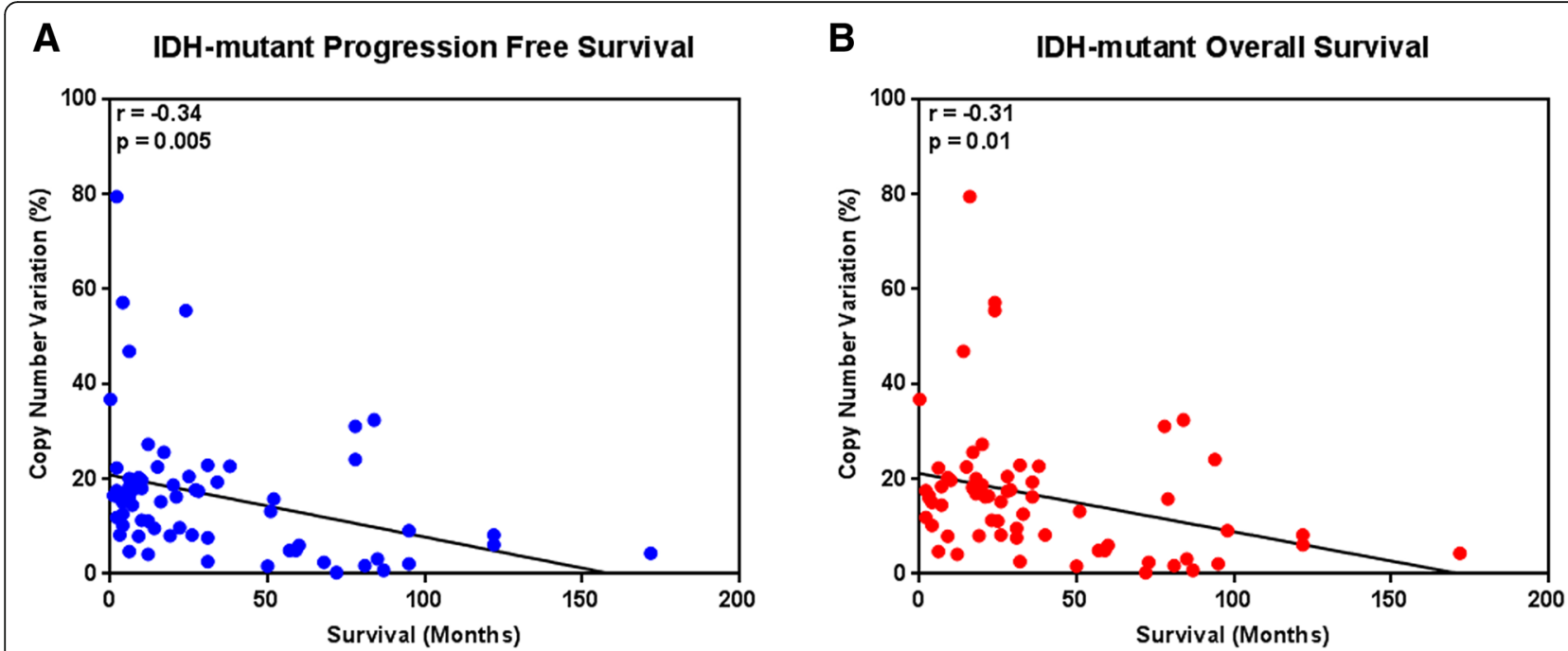

Fig. 4 Scatter plots of copy number variation (\%) plotted against survival time (months) in grouped IDH-mutant LGGs and IDH-mutant GBMs with Pearson's R values, illustrating significant inverse correlations between the two data points in terms of (a) progression-free survival $(r=-0.3415$; $p=0.0047)$ and $(\mathbf{b})$ overall survival $(r=-0.3098 ; p=0.0102)$

compared to all $I D H$-mutant tumors with poor prognosis (groups 2 and 3 combined) $(p=0.0211)$. No significant difference was observed between groups 2 and 3 $(p=0.3475)$ or between the $I D H$-wildtype groups 4 and 5 ( $p=0.7681)$ (Fig. 8a).

\section{Mutation analysis}

Overall mutation load did not differ significantly between any of the tumor groups analyzed (group 1 vs group 2, $p=0.3863$; group 1 vs group $3, p=0.2745$; group 2 vs group $3, p=0.2728$; group 3 vs group $5, p=0.3318$; or group 4 vs group $5, p=0.5627$ ) (Fig. 3b, d).
Analysis of individual genes in the $I D H$-mutant groups reveals consistently high rates of TP53 mutations in all 3 groups (91-100\% of cases) and relatively high rates of ATRX mutations (68-77\% of cases). There are other scattered pathogenic mutations, with elevated numbers of EGFR (14\%) and PIK3R1 (27\%) mutations in the IDH-mutant GBM group (Additional file 1: Figure S1, Additional file 2: Figure S2 and Additional file 3: Figure S3).

The $I D H$-wildtype tumor groups have significantly lower rates of ATRX mutation in both the LGG group (4\%) and GBM group (0\%), as well as lower rates of TP53 mutations in the LGG group (20\%) and GBM

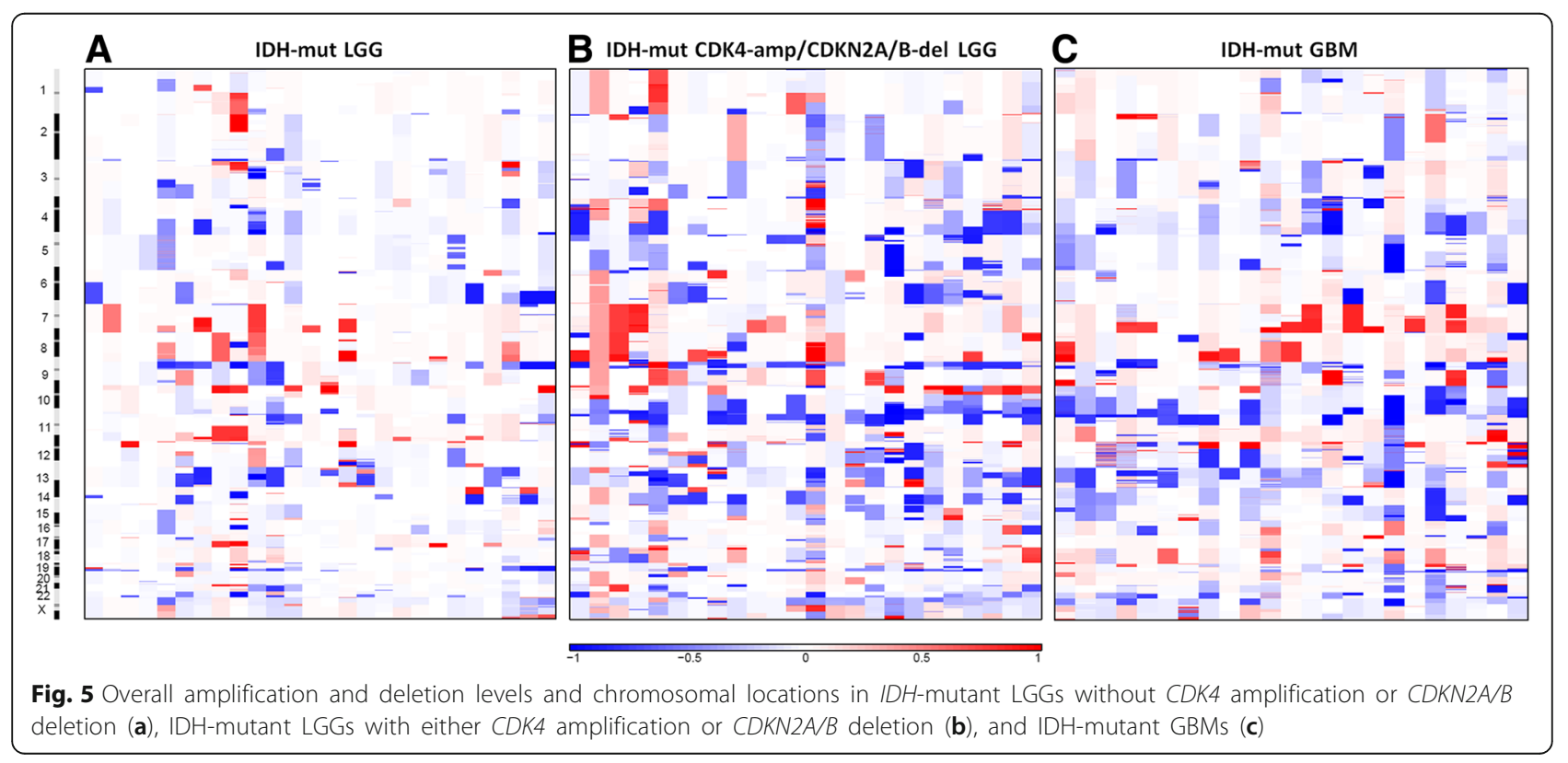




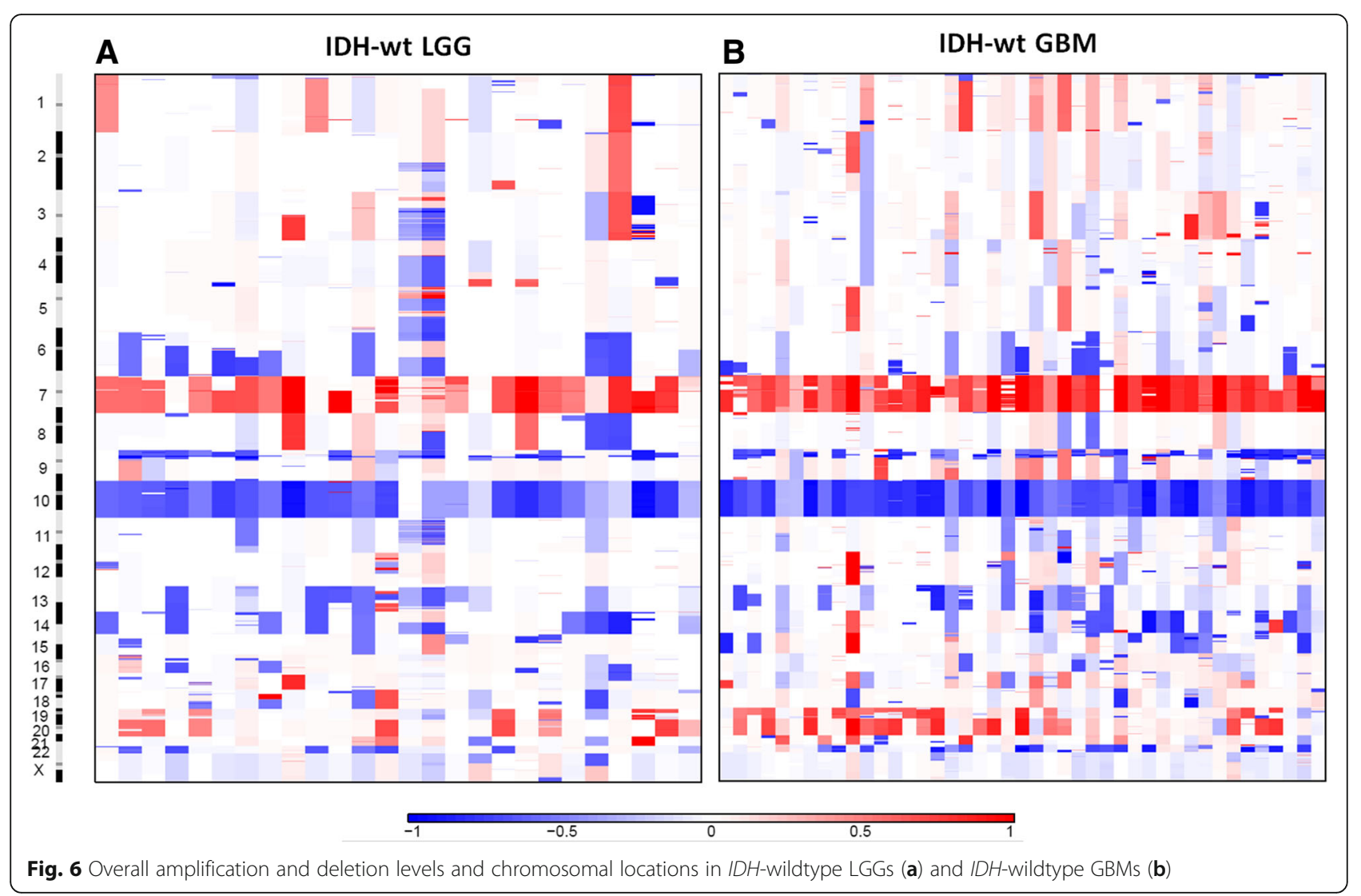

group (33\%). Mutations in EGFR (32\% in LGG; $24 \%$ in GBM), PTEN (28\% in LGG; $31 \%$ in GBM), NF1 (32\% in LGG; $7 \%$ in GBM), and RB1 (12\% in LGG; $12 \%$ in GBM) were seen significantly more frequently in these tumors than in the $I D H$-mutant groups $1-3$ (Additional file 4: Figure S4 and Additional file 5: Figure S5).

\section{Mutation analysis of genes associated with overall genomic instability}

Using a 43-gene panel of genes known to be associated with chromosomal instability (excluding TP53 due to its relative frequency across all groups), we detected a significant difference in the number of mutations between group 1 IDH-mutant LGGs without CDK4 amplifications or $C D K N 2 A / B$ deletions and group $2 I D H$-mutant LGGs with either alteration $(p=0.0197)$ as well as between group $1 \mathrm{IDH}$-mutant LGGs and group $3 \mathrm{IDH}$-mutant GBMs $(p=0.0086)$ (Fig. 8b). No significant difference was identified between the two groups of IDH-wildtype astrocytomas $(p=0.5443)$. No significant difference was identified between $I D H$-mutant tumors with poor outcomes (group $2+3$ ) and $I D H$-wildtype tumors with poor prognosis (group $4+5)(p=0.1297)$, although there was a trend toward fewer mutations in genes specifically associated with chromosomal instability in the $I D H$-wildtype groups (Tables 1 and 2). These data mirror the trend in level of total CNV and chromothripsis identified in each tumor group.

\section{Discussion}

Diffuse gliomas represent approximately $27 \%$ of all primary brain tumors and approximately $81 \%$ of all malignant brain tumors [29, 30], making them an intense subject of study and public health expenditure. The recent changes to glioma classification in the 2016 WHO classification system are based around the beneficial role of $\mathrm{IDH}$-mutation in gliomas [25]; however, significant molecular heterogeneity exists within the lowergrade $I D H$-mutant and wildtype gliomas. More work is necessary to further stratify $I D H$-mutant astrocytomas [44], and there is evidence that many $I D H 1 / 2$-wildtype LGGs may be biologically identical to $I D H 1 / 2$-wildtype glioblastomas $[17,34]$. In addition, new methods to analyze whole genome genetic and epigenetic signatures are leading to new definitions for many of these tumor groups with significant prognostic implications [4, 38, 43].

We previously reported that increased CNV is associated with a more aggressive biological behavior and poor overall survival in $I D H$-mutant LGGs [36, 37]. With whole genome analysis in the current study, we show 

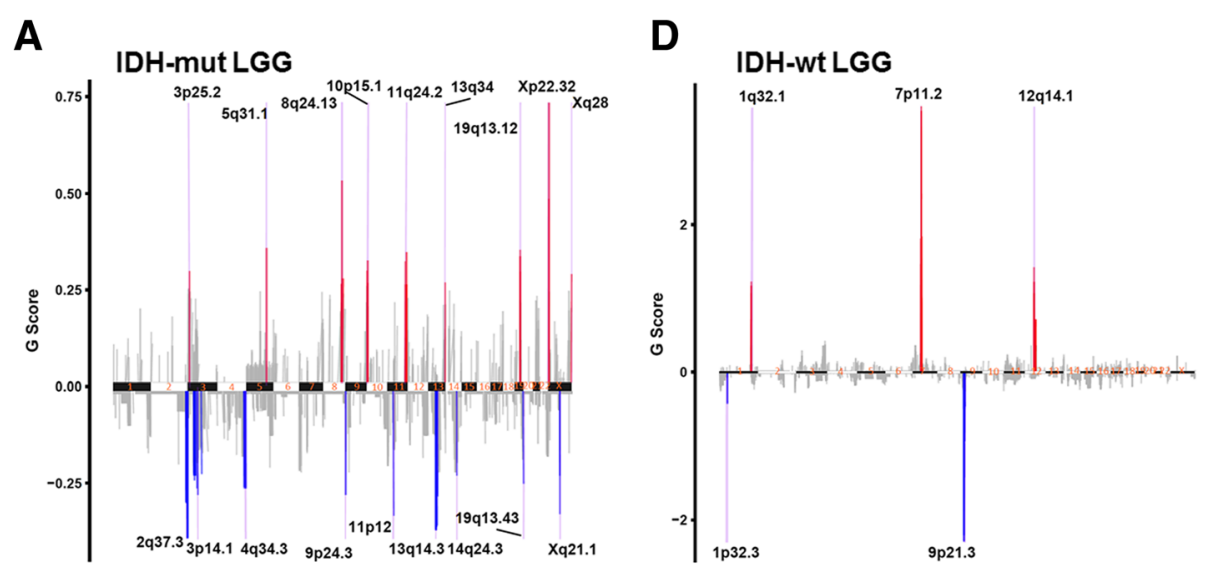

B

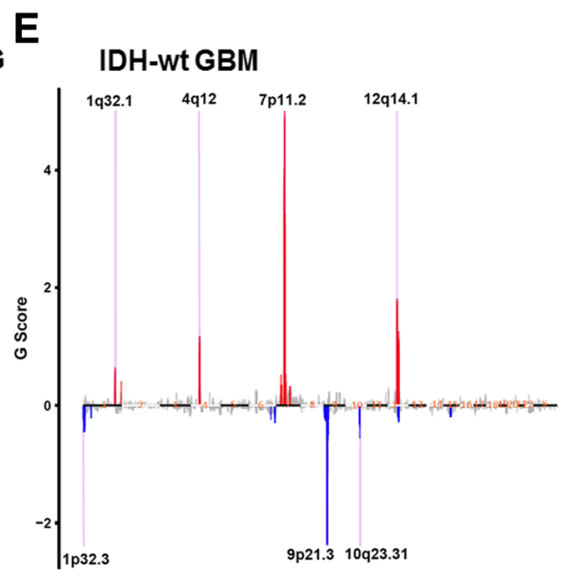

C
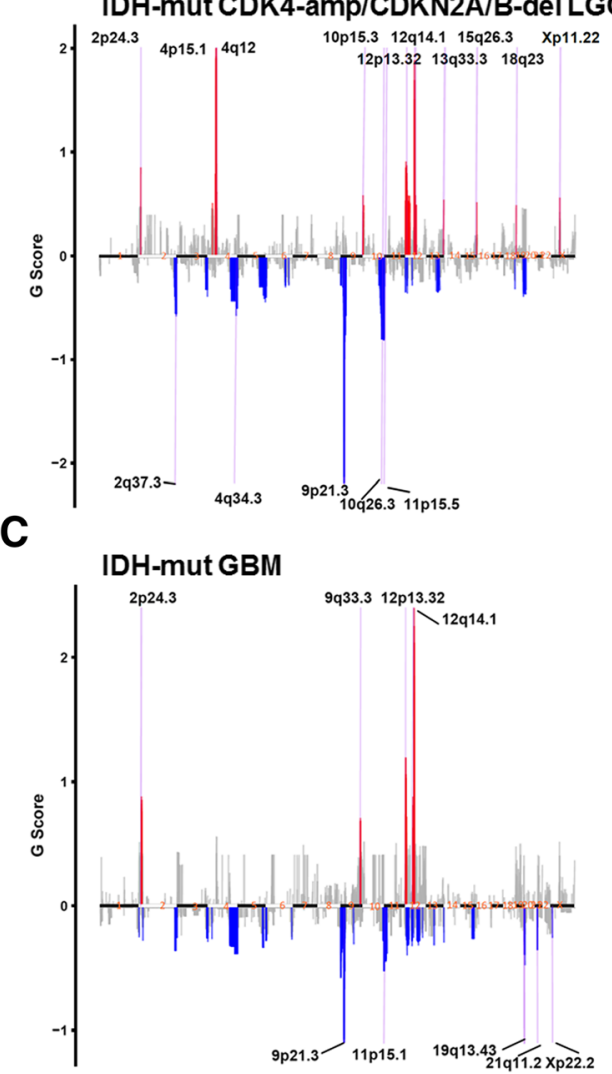

Fig. 7 GISTIC analysis showing the most consistent and relevant cytoband alterations in IDH-mutant LGGs without CDK4 amplification or CDKN2A/B deletion (a), IDH-mutant LGGs with either CDK4 amplification or CDKN2A/B deletion (b), IDH-mutant GBMs (c), IDH-wildtype LGGs (d), and IDH-wildtype GBMs (e). All cytobands shown met the criterion of false discovery rate (FDR) $\leq 0.25$. The annotated cytobands met the criterion of FDR $\leq 0.05$

that $\mathrm{CNV}$ correlates with clinical outcome, and was significantly lower in the $I D H$-mutant LGGs compared to the $I D H$-mutant LGGs with $C D K 4$ or $C D K N 2 A / B$ alterations or $I D H$-mutant GBMs. (Figs. 3a and 4). These results confirm our previous findings, in which $I D H$ mutant LGG cases selected solely on the basis of poor clinical outcome displayed significantly higher levels of $\mathrm{CNV}$ before progression to GBM than a cohort with more conventional progression-free and overall survival
[36]. The elevated CNV levels in IDH-mutant LGGs with $C D K 4$ or $C D K N 2 A / B$ alterations and $I D H$-mutant GBM represent a heterogenous assortment of genomic alterations within the $I D H$-mutant group with only a few consistent areas of gains and losses (Fig. 5b-c) whereas a large fraction of the $\mathrm{CNV}$ in $I D H$-wildtype tumors arose from consistent amplifications in chromosome $7 \mathrm{p}$ (containing EGFR), and deletions in chromosomes 9p and 10 (Fig. 6). 


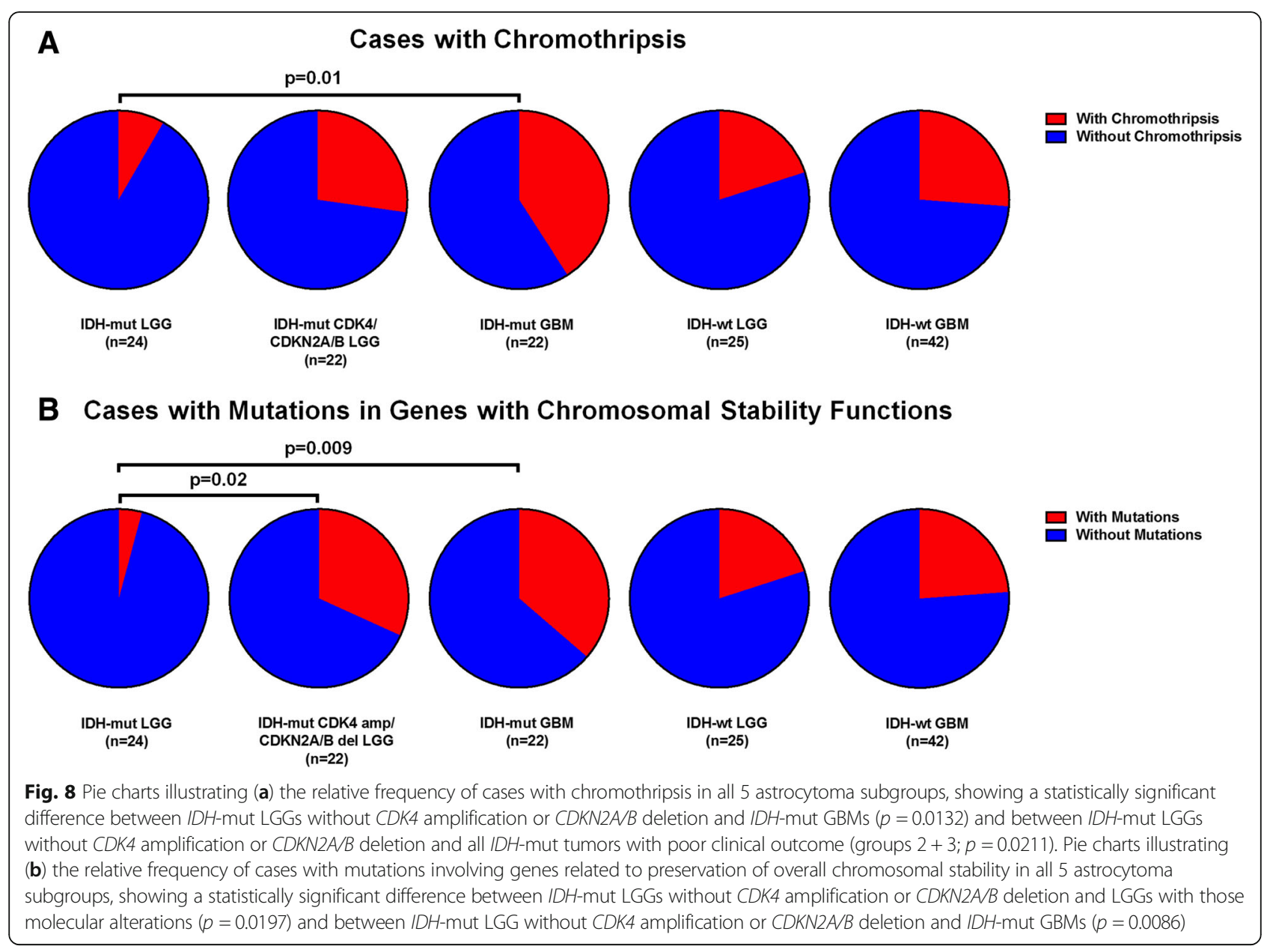

Although the overall $\mathrm{CNV}$ changes seem to occur before histologic progression to GBM in cases with other negative prognostic factors and/or clinically demonstrated poor outcomes, there is still uncertainty in the exact connection to elevated levels of $\mathrm{CNV}$ and the driving force behind this poor progression. Our data also agrees with the previously demonstrated data that $C D K 4$ and $C D K N 2 A / B$ alterations are prognostic factors within the IDH-mutant LGGs [44]. While worse prognosis seems to correlate with $C D K 4$ or $C D K N 2 A / B$ status, our earlier study [36] showed only a fraction of the rapidly progressing tumors had these specific alterations, yet all of them had high overall $\mathrm{CNV}$, indicating that it may be an earlier event or a separate phenomenon altogether. Further analysis of CNV data may help determine if the $I D H$-mutant LGGs with CDK4 and/or CDKN2A/Balterations are actually early GBMs or simply undersampled tumors, similar to current thinking on many

Table 2 Summary of mutations in genes with known functions related to maintaining DNA and chromosomal stability for each group

\begin{tabular}{lll}
\hline Group & Tumor Type & $\begin{array}{l}\text { Mutations in genes with functions related to maintaining } \\
\text { overall genome/chromosomal stability }\end{array}$ \\
\hline 1 & IDH-mut LGG & BRCA2 \\
2 & IDH-mut CDK4/ & \\
3 & CDKN2AB LGG & APC, ATM, FANCB, FANCD2, RAD51 (2), TOP1 \\
4 & IDH-mut GBM & APC (4), BLM, BRCA2, SMC1 (2) \\
5 & IDH-wt LGG & BLM, FANCB (2), FANCE, LIG4 \\
\hline
\end{tabular}


IDH-wildtype LGGs [3, 42]. While it is reasonable to argue that our cohort of $I D H$-mutant LGGs without $C D K 4$ or $C D K N 2 A / B$ alterations show low $C N V$ because they selectively exclude tumors with specific known amplifications/deletions to enrich the other cohorts, if this were to hold true, the clinical outcome would likely also follow the same pattern and would show worse outcome within the other groups containing $C D K 4$ amplification or $C D K N 2 A / B$ deletion. $C D K 4$ and $C D K N 2 A / B$ did not show a prognostic difference in $I D H$-mutant GBMs or $I D H$-wildtype LGGs or GBMs, and the overall CNV was not different between these two groups (Fig. 2a-c), so the effect of both of these alterations seems limited to IDH-mutant LGG cases. CDK4 amplification and $C D K N 2 A / B$ deletion also appear to be mutually exclusive, with only two total cases $(2.3 \%)$ having both molecular alterations (Additional file 4: Figure S4 and Additional file 5: Figure S5).

An additional finding in these tumor groups is the trend toward more frequent mutations in genes associated with overall chromosomal stability in groups with worse clinical outcomes (groups 2-5) compared to the group with relatively favorable outcomes (group 1) (Fig. 8b, Table 2). This correlates positively with the trends toward increased CNV levels and number of cases with chromothripsis and inversely with the progression-free and overall survival in these groups (Table 1). The number of mutations in genes with chromosomal stability functions and cases with chromothripsis are somewhat lower in the $I D H$-wildtype cohorts compared to groups 2 and 3 in the $I D H$-mutant cohorts, despite having statistically identical CNV levels (Fig. 8). This difference may be explained by the fact that a large portion of the $\mathrm{CNV}$ in these $I D H$-wildtype groups is more homogeneously associated with specific chromosomal regions $(7,9 p, 10)$ instead of more diffusely distributed as seen in the $I D H$-mutant groups with high $\mathrm{CNV}$ and poor outcome (Figs. 5 and 6).

This process also provides a potential mechanistic explanation for the widespread genomic alterations and the worse prognosis associated with this increase in $\mathrm{CNV}$ in at least a subset of cases. Inactivating mutations in genes associated with maintenance of genetic and chromosomal integrity, and the resulting increase in $\mathrm{CNV}$, allows for rapid and widespread changes to the genome, including chromothripsis, and has the potential to cause more frequent gains of oncogenes and loss of tumor suppressor genes and drive tumor formation and progression towards malignancy $[11,19,20,41,46]$. This may also suggest a different molecular mechanism underlying total $\mathrm{CNV}$ levels in $I D H$-mutant and $I D H$ wildtype groups. At this point, however, we can only state that these factors are all correlated with poor clinical outcome, but no causative links can definitively be made.
The present study reinforces our previous findings $[36,37]$ demonstrating that elevated CNV is associated with poor outcome in grade II and III IDH-mutant astrocytomas, and presents this as a potential prognostic factor. We demonstrate for the first time that higher $\mathrm{CNV}$ is associated with previously established prognostic factors within the IDH-mutant LGG subgroup, such as CDK4 amplification and $C D K N 2 A / B$ deletion. This study is also the first to demonstrate a significant quantitative difference in mutations of genes related to chromosomal stability in groups with higher $\mathrm{CNV}$ and worse clinical outcomes (Fig. 8b).

It is important to note that while many of the genetic and epigenetic methods used to generate these data are currently only used for research purposes, recent proof-of-concept studies have demonstrated that specific and large-scale genetic and epigenetic alterations can be identified rapidly and relatively inexpensively $[12,18]$, including overall methylation patterns indicative of $I D H 1 / 2$ status, methylation of key gene promotors, $\mathrm{CNV}$, mutations, and gains and losses of key genes and chromosomal regions. These studies have demonstrated that with newer techniques these molecular factors can be identified in approximately the time that it takes to make a histologic diagnosis. It is therefore conceivable that $\mathrm{CNV}$ and other molecular factors identified in this report could soon be used clinically at the time of initial diagnosis to help guide prognosis and treatment strategies.

\section{Conclusions}

Our results support our previous findings that IDHmutant lower-grade astrocytomas with higher total $\mathrm{CNV}$ are associated with poor clinical outcome and behave more consistently with $I D H$-mutant GBM than other IDH-mutant LGGs with low CNV, and suggest that $\mathrm{CNV}$ could be a viable prognostic factor in these tumors alongside $I D H 1 / 2$ mutations, $C D K 4$ amplifications, and $C D K N 2 A / B$ deletions. We demonstrated that high $\mathrm{CNV}$ occurs in $I D H 1 / 2$-wildtype astrocytomas and glioblastomas which also have poor prognoses, although the reason underlying elevated CNV may be different in $I D H$-mutant and $I D H$-wildtype tumors. We also provide a possible mechanism for the overall CNV differences in these astrocytoma subgroups, as the CNV levels seem to correlate with numbers of mutations in genes with roles in maintaining genomic stability. These results suggest that high overall CNV negate the beneficial effects of IDH1/2 mutation, and could potentially be used as a prognostic marker in $I D H$-mutant astrocytomas in the future. 


\section{Additional files}

Additional file 1: Figure S1. Summary plot showing the frequency of genes with pathologic mutations and amplifications, IDH-mutant LGGs without CDK4 amplification or CDKN2A/B deletion. (TIF $91 \mathrm{~kb}$ )

Additional file 2: Figure S2. Summary plot showing the frequency of genes with pathologic mutations and amplifications/deletions, IDH-mutant LGGs with either CDK4 amplification or CDKN2A/B deletion. (TIF 90 kb)

Additional file 3: Figure S3. Summary plot showing the frequency of genes with pathologic mutations and amplifications/deletions, IDH-mutant GBMs. (TIF 86 kb)

Additional file 4: Figure S4. Summary plot showing the frequency of genes with pathologic mutations and amplifications/deletions, IDH-wildtype LGGs. (TIF 95 kb)

Additional file 5: Figure S5. Summary plot showing the frequency of genes with pathologic mutations and amplifications/deletions, IDH-wildtype GBMs. (TIF $140 \mathrm{~kb}$ )

\section{Acknowledgements}

Not applicable.

\section{Authors' contributions}

Conception of the work: KJH, TER. Design of the work: KM, JMW, MSV, MS, $\mathrm{KJH}$, TER. Acquisition/analysis/interpretation of the data: KM, AAS, MSV, CX, $\mathrm{KJH}$, TER. Creation of new software used in the work: not applicable. Drafted the work or substantively revised it: KM, JMW, YF, KG, MSV, RJC, KJH, TER. All authors read and approved the final manuscript.

Authors' information

Not applicable.

\section{Funding}

M.S. is supported in part by a Friedberg Charitable Foundation.

\section{Availability of data and materials}

The full dataset used in this study is freely available at www.cbioportal.org and https://www.cancer.gov/about-nci/organization/ccg/research/structuralgenomics/tcga.

\section{Ethics approval and consent to participate}

Not applicable.

\section{Consent for publication}

Not applicable.

\section{Competing interests}

The authors declare that they have no competing interests.

\section{Author details}

${ }^{1}$ Department of Pathology, State University of New York, Upstate Medical University, Syracuse, NY 13210, USA. Eugene McDermott Center for Human Growth \& Development, University of Texas Southwestern Medical Center, Dallas, TX 75390, USA. ${ }^{3}$ Department of Pathology, University of Texas Health Science Center, San Antonio, TX 78229, USA. ${ }^{4}$ Glenn Biggs Institute for Alzheimer's \& Neurodegenerative Diseases, University of Texas Health Science Center, San Antonio, TX 78229, USA. ${ }^{5}$ Department of Neuroscience and Physiology, State University of New York, Upstate Medical University, Syracuse, NY 13210, USA. 'Department of Neurosurgery, State University of New York, Upstate Medical University, Syracuse, NY 13210, USA. 7 Department of Pathology, New York University Langone Medical Center, New York City, NY 10016, USA. ${ }^{8}$ Department of Bioinformatics, University of Texas Southwestern Medical Center, Dallas, TX 75390, USA. ${ }^{9}$ Department of Population and Data Sciences, University of Texas Southwestern Medical Center, Dallas, TX 75390, USA. ${ }^{10}$ Department of Pathology, University of Texas Southwestern Medical Center, Dallas, TX 75390, USA.
Received: 12 April 2019 Accepted: 20 May 2019

Published online: 10 June 2019

\section{References}

1. Aoki K, Nakamura H, Suzuki H, Matsuo K, Kataoka K, Shimamura T, Motomura K, Ohka F, Shiina S, Yamamoto T et al (2018) Prognostic relevance of genetic alterations in diffuse lower-grade gliomas. NeuroOncology 20:66-77. https://doi.org/10.1093/neuonc/nox132

2. Beroukhim R, Getz G, Nghiemphu L, Barretina J, Hsueh T, Linhart D, Vivanco I, Lee JC, Huang JH, Alexander S et al (2007) Assessing the significance of chromosomal aberrations in cancer: methodology and application to glioma. Proc Natl Acad Sci U S A 104:20007-20012. https://doi.org/10.1073/ pnas.0710052104

3. Brat DJ, Aldape K, Colman H, Holland EC, Louis DN, Jenkins RB, Kleinschmidt-DeMasters BK, Perry A, Reifenberger G, Stupp R et al (2018) CIMPACT-NOW update 3: recommended diagnostic criteria for "diffuse astrocytic glioma, IDH-wildtype, with molecular features of glioblastoma, WHO grade IV". Acta Neuropathol 136:805-810. https://doi.org/10.1007/ s00401-018-1913-0

4. Cancer Genome Atlas Research N, Brat DJ, Verhaak RG, Aldape KD, Yung WK, Salama SR, Cooper LA, Rheinbay E, Miller CR, Vitucci M et al (2015) Comprehensive, integrative genomic analysis of diffuse lower-grade gliomas. N Engl J Med 372:2481-2498. https://doi.org/10.1056/ NEJMoa1402121

5. Ceccarelli M, Barthel FP, Malta TM, Sabedot TS, Salama SR, Murray BA, Morozova O, Newton Y, Radenbaugh A, Pagnotta SM et al (2016) Molecular Profiling Reveals Biologically Discrete Subsets and Pathways of Progression in Diffuse Glioma. Cell 164:550-563. https://doi.org/10.1016/j.cell.2015.12.028

6. Cerami E, Gao J, Dogrusoz U, Gross BE, Sumer SO, Aksoy BA, Jacobsen A, Byrne CJ, Heuer ML, Larsson E et al (2012) The cBio cancer genomics portal: an open platform for exploring multidimensional cancer genomics data. Cancer Discov 2:401-404. https://doi.org/10.1158/2159-8290.CD-12-0095

7. Chan SH, Ngeow J (2017) Germline mutation contribution to chromosomal instability. Endocr Relat Cancer 24:T33-T46. https://doi.org/10.1530/ERC-170062

8. Cimino PJ, Zager M, McFerrin L, Wirsching HG, Bolouri H, Hentschel B, von Deimling A, Jones D, Reifenberger G, Weller M et al (2017) Multidimensional scaling of diffuse gliomas: application to the 2016 World Health Organization classification system with prognostically relevant molecular subtype discovery. Acta Neuropathol Commun 5:39. https://doi.org/10.1186/ s40478-017-0443-7

9. Cohen A, Sato M, Aldape K, Mason CC, Alfaro-Munoz K, Heathcock L, South ST, Abegglen LM, Schiffman JD, Colman H (2015) DNA copy number analysis of grade II-III and grade IV gliomas reveals differences in molecular ontogeny including chromothripsis associated with IDH mutation status. Acta Neuropathol Commun 3:34. https://doi.org/10.1186/s40478-015-0213-3

10. Colaprico A, Silva TC, Olsen C, Garofano L, Cava C, Garolini D, Sabedot TS, Malta TM, Pagnotta SM, Castiglioni I et al (2016) TCGAbiolinks: an R/ Bioconductor package for integrative analysis of TCGA data. Nucleic Acids Res 44:e71. https://doi.org/10.1093/nar/gkv1507

11. de Tayrac M, Etcheverry A, Aubry M, Saikali S, Hamlat A, Quillien V, Le Treut A, Galibert MD, Mosser J (2009) Integrative genome-wide analysis reveals a robust genomic glioblastoma signature associated with copy number driving changes in gene expression. Genes Chromosomes Cancer 48:55-68. https://doi.org/10.1002/gcc.20618

12. Euskirchen $P$, Bielle F, Labreche $K$, Kloosterman WP, Rosenberg S, Daniau M, Schmitt C, Masliah-Planchon J, Bourdeaut F, Dehais C et al (2017) Same-day genomic and epigenomic diagnosis of brain tumors using real-time nanopore sequencing. Acta Neuropathol 134:691-703. https://doi.org/10. 1007/s00401-017-1743-5

13. Forbes SA, Bindal N, Bamford S, Cole C, Kok CY, Beare D, Jia M, Shepherd R, Leung K, Menzies A et al (2011) COSMIC: mining complete cancer genomes in the catalogue of somatic mutations in Cancer. Nucleic Acids Res 39: D945-D950. https://doi.org/10.1093/nar/gkq929

14. Gao J, Aksoy BA, Dogrusoz U, Dresdner G, Gross B, Sumer SO, Sun Y, Jacobsen A, Sinha R, Larsson E et al (2013) Integrative analysis of complex cancer genomics and clinical profiles using the cBioPortal. Sci Signal 6:11. https://doi.org/10.1126/scisignal.2004088

15. Genomes Project C, Abecasis GR, Auton A, Brooks LD, DePristo MA, Durbin RM, Handsaker RE, Kang HM, Marth GT, McVean GA (2012) An integrated 
map of genetic variation from 1,092 human genomes. Nature 491:56-65. https://doi.org/10.1038/nature11632

16. Glover TW, Wilson TE, Arlt MF (2017) Fragile sites in cancer: more than meets the eye. Nat Rev Cancer 17:489-501. https://doi.org/10.1038/nrc. 2017.52

17. Hasselblatt M, Jaber M, Reuss D, Grauer O, Bibo A, Terwey S, Schick U, Ebel H, Niederstadt T, Stummer W et al (2018) Diffuse astrocytoma, IDH-wildtype: a dissolving diagnosis. J Neuropathol Exp Neurol 77:422-425. https://doi. org/10.1093/jnen/nly012

18. Hench J, Bihl M, Bratic Hench I, Hoffmann P, Tolnay M, Bosch Al Jadooa N, Mariani L, Capper D, Frank S (2018) Satisfying your neuro-oncologist: a fast approach to routine molecular glioma diagnostics. Neuro-Oncology 20: 1682-1683. https://doi.org/10.1093/neuonc/noy128

19. Jeuken J, van den Broecke C, Gijsen S, Boots-Sprenger S, Wesseling P (2007) RAS/RAF pathway activation in gliomas: the result of copy number gains rather than activating mutations. Acta Neuropathol 114:121-133. https://doi, org/10.1007/s00401-007-0239-0

20. Jones MJ, Jallepalli PV (2012) Chromothripsis: chromosomes in crisis. Dev Cell 23:908-917. https://doi.org/10.1016/j.devcel.2012.10.010

21. Korbel JO, Campbell PJ (2013) Criteria for inference of chromothripsis in cancer genomes. Cell 152:1226-1236. https://doi.org/10.1016/..cell.2013. 02.023

22. Landrum MJ, Lee JM, Benson M, Brown G, Chao C, Chitipiralla S, Gu B, Hart J, Hoffman D, Hoover J et al (2016) ClinVar: public archive of interpretations of clinically relevant variants. Nucleic Acids Res 44:D862-D868. https://doi. org/10.1093/nar/gkv1222

23. Li J, Duncan DT, Zhang B (2010) CanProVar: a human cancer proteome variation database. Hum Mutat 31:219-228. https:/doi.org/10.1002/humu. 21176

24. Li ZH, Guan YL, Liu Q, Wang Y, Cui R, Wang YJ (2019) Astrocytoma progression scoring system based on the WHO 2016 criteria. Sci Rep 9:96. https://doi.org/10.1038/s41598-018-36471-4

25. Louis DN, Perry A, Reifenberger G, von Deimling A, Figarella-Branger D, Cavenee WK, Ohgaki H, Wiestler OD, Kleihues P, Ellison DW (2016) The 2016 World Health Organization classification of tumors of the central nervous system: a summary. Acta Neuropathol 131:803-820. https://doi.org/10.1007/ s00401-016-1545-1

26. Mayakonda A, Lin DC, Assenov Y, Plass C, Koeffler HP (2018) Maftools: efficient and comprehensive analysis of somatic variants in cancer. Genome Res 28:1747-1756. https://doi.org/10.1101/gr.239244.118

27. Mermel CH, Schumacher SE, Hill B, Meyerson ML, Beroukhim R, Getz G (2011) GISTIC2.0 facilitates sensitive and confident localization of the targets of focal somatic copy-number alteration in human cancers. Genome Biol 12 R41. https://doi.org/10.1186/gb-2011-12-4-r41

28. Olar A, Wani KM, Alfaro-Munoz KD, Heathcock LE, van Thuijl HF, Gilbert MR, Armstrong TS, Sulman EP, Cahill DP, Vera-Bolanos E et al (2015) IDH mutation status and role of WHO grade and mitotic index in overall survival in grade II-III diffuse gliomas. Acta Neuropathol 129:585-596. https://doi.org/ 10.1007/s00401-015-1398-z

29. Ostrom QT, Gittleman H, Liao P, Vecchione-Koval T, Wolinsky Y, Kruchko C, Barnholtz-Sloan JS (2017) CBTRUS statistical report: primary brain and other central nervous system tumors diagnosed in the United States in 20102014. Neuro-Oncology 19:v1-v88. https://doi.org/10.1093/neuonc/nox158

30. Ostrom QT, Gittleman H, Truitt G, Boscia A, Kruchko C, Barnholtz-Sloan JS (2018) CBTRUS statistical report: primary brain and other central nervous system tumors diagnosed in the United States in 2011-2015. NeuroOncology 20:iv1-iv86. https://doi.org/10.1093/neuonc/noy131

31. Parsons DW, Jones $S$, Zhang $X$, Lin JC, Leary RJ, Angenendt P, Mankoo P, Carter H, Siu IM, Gallia GL et al (2008) An integrated genomic analysis of human glioblastoma multiforme. Science 321:1807-1812. https://doi.org/10. 1126/science.1164382

32. Reich M, Liefeld T, Gould J, Lerner J, Tamayo P, Mesirov JP (2006) GenePattern 2.0. Nat Genet 38:500-501. https://doi.org/10.1038/ng0506-500

33. Reis GF, Pekmezci M, Hansen HM, Rice T, Marshall RE, Molinaro AM, Phillips JJ, Vogel H, Wiencke JK, Wrensch MR et al (2015) CDKN2A loss is associated with shortened overall survival in lower-grade (World Health Organization grades II-III) astrocytomas. J Neuropathol Exp Neurol 74:442-452. https://doi. org/10.1097/NEN.0000000000000188

34. Reuss DE, Kratz A, Sahm F, Capper D, Schrimpf D, Koelsche C, Hovestadt V, Bewerunge-Hudler M, Jones DT, Schittenhelm J et al (2015) Adult IDH wild type astrocytomas biologically and clinically resolve into other tumor entities. Acta Neuropathol 130:407-417. https://doi.org/10.1007/s00401-0151454-8

35. Reuss DE, Mamatjan Y, Schrimpf D, Capper D, Hovestadt V, Kratz A, Sahm F, Koelsche C, Korshunov A, Olar A et al (2015) IDH mutant diffuse and anaplastic astrocytomas have similar age at presentation and little difference in survival: a grading problem for WHO. Acta Neuropathol 129: 867-873. https://doi.org/10.1007/s00401-015-1438-8

36. Richardson TE, Sathe AA, Kanchwala M, Jia G, Habib AA, Xiao G, Snuderl M, Xing C, Hatanpaa KJ (2018) Genetic and epigenetic features of rapidly progressing IDH-mutant Astrocytomas. J Neuropathol Exp Neurol 77:542548. https://doi.org/10.1093/jnen/nly026

37. Richardson TE, Snuderl M, Serrano J, Karajannis MA, Heguy A, Oliver D, Raisanen JM, Maher EA, Pan E, Barnett S et al (2017) Rapid progression to glioblastoma in a subset of IDH-mutated astrocytomas: a genome-wide analysis. J Neuro-Oncol 133:183-192. https://doi.org/10.1007/s1 1060-017-2431-y

38. Sahm F, Schrimpf D, Jones DT, Meyer J, Kratz A, Reuss D, Capper D, Koelsche C, Korshunov A, Wiestler B et al (2016) Next-generation sequencing in routine brain tumor diagnostics enables an integrated diagnosis and identifies actionable targets. Acta Neuropathol 131:903-910. https://doi.org/10.1007/s00401-015-1519-8

39. Sherry ST, Ward MH, Kholodov M, Baker J, Phan L, Smigielski EM, Sirotkin K (2001) dbSNP: the NCBI database of genetic variation. Nucleic Acids Res 29: 308-311

40. Shihab HA, Rogers MF, Gough J, Mort M, Cooper DN, Day IN, Gaunt TR, Campbell C (2015) An integrative approach to predicting the functional effects of non-coding and coding sequence variation. Bioinformatics 31: 1536-1543. https://doi.org/10.1093/bioinformatics/btv009

41. Stephens PJ, Greenman CD, Fu B, Yang F, Bignell GR, Mudie LJ, Pleasance ED, Lau KW, Beare D, Stebbings LA et al (2011) Massive genomic rearrangement acquired in a single catastrophic event during cancer development. Cell 144:27-40. https://doi.org/10.1016/j.cell.2010.11.055

42. Stichel D, Ebrahimi A, Reuss D, Schrimpf D, Ono T, Shirahata M, Reifenberger G, Weller M, Hanggi D, Wick W et al (2018) Distribution of EGFR amplification, combined chromosome 7 gain and chromosome 10 loss, and TERT promoter mutation in brain tumors and their potential for the reclassification of IDHwt astrocytoma to glioblastoma. Acta Neuropathol 136:793-803. https://doi.org/10.1007/s00401-018-1905-0

43. Sturm D, Bender S, Jones DT, Lichter P, Grill J, Becher O, Hawkins C, Majewski J, Jones C, Costello JF et al (2014) Paediatric and adult glioblastoma: multiform (epi) genomic culprits emerge. Nat Rev Cancer 14: 92-107. https://doi.org/10.1038/nrc3655

44. Velazquez Vega JE, Brat DJ (2018) Incorporating advances in molecular pathology into brain tumor diagnostics. Adv Anat Pathol 25:143-171. https://doi.org/10.1097/PAP.0000000000000186

45. Yan H, Parsons DW, Jin G, McLendon R, Rasheed BA, Yuan W, Kos I, BatinicHaberle I, Jones S, Riggins GJ et al (2009) IDH1 and IDH2 mutations in gliomas. N Engl J Med 360:765-773. https://doi.org/10.1056/NEJMoa0808710

46. Zhang CZ, Leibowitz ML, Pellman D (2013) Chromothripsis and beyond: rapid genome evolution from complex chromosomal rearrangements. Genes Dev 27:2513-2530. https://doi.org/10.1101/gad.229559.113

\section{Publisher's Note}

Springer Nature remains neutral with regard to jurisdictional claims in published maps and institutional affiliations.

Ready to submit your research? Choose BMC and benefit from:

- fast, convenient online submission

- thorough peer review by experienced researchers in your field

- rapid publication on acceptance

- support for research data, including large and complex data types

- gold Open Access which fosters wider collaboration and increased citations

- maximum visibility for your research: over $100 \mathrm{M}$ website views per year

At BMC, research is always in progress.

Learn more biomedcentral.com/submissions 